\title{
Análise da preparação do Plasma-Rico em Plaquetas por meio da modelagem e simulação da etapa de centrifugação e da determinação do raio das fibras de fibrina formadas na ativação
}

\author{
Edson R. Onaga (IC), Sofia E. M. Galdames (PG), Maria H. A. Santana (PQ)
}

\section{Resumo}

O Plasma Rico em Plaquetas (PRP) é uma preparação autóloga usada em várias terapias no campo da medicina regenerativa. A preparação do PRP envolve duas etapas principais: a de centrifugação para separação das células vermelhas do sangue e a etapa de ativação das plaquetas para liberação dos fatores de crescimento, que são os componentes ativos na regeneração dos tecidos. Embora não trivial nesse tipo de processo, a modelagem e simulação torna-se uma ferramenta importante. Neste trabalho, a influência dos anticoagulantes ACD-A e citrato de sódio usados na coleta do sangue foi analisada, nas etapas de centrifugação e ativação, por meio da modelagem e simulação dos processos.

Palavras Chave: plasma rico em plaquetas, rede de fibrina, centrifugação.

\section{Introdução}

O Plasma Rico em Plaquetas (PRP) é um produto autólogo, não imunogênico, preparado a partir do sangue total. Trata-se de um concentrado de plaquetas em uma fração reduzida de plasma do sangue humano. As plaquetas são ricas em fatores de crescimento, que são capazes de estimular e acelerar a regeneração tecidual. Terapias com PRP têm sido aplicadas com sucesso nas áreas de ortopedia, odontologia e dermatologia dentre outras.

A preparação do PRP envolve três etapas consecutivas: coleta de sangue, separação das células vermelhas, geralmente feita por centrifugação, e ativação das plaquetas concentradas no sobrenadante, para liberação dos fatores de crescimento. ACD-A (mistura de ácido cítrico, citrato de sódio e dextrose) e citrato de sódio (CIT) são atualmente os anticoagulantes mais usados na coleta de sangue, porém a sua influência na preparação do PRP ainda não é bem determinada. Devido ao grande número de variáveis envolvidas na preparação do PRP, a modelagem e simulação torna-se uma ferramenta importante na análise do comportamento das principais variáveis envolvidas no processo. Portanto, o objetivo deste trabalho foi analisar a influência de anticoagulantes na preparação do PRP por meio de modelagem e simulação dos processos envolvidos.

\section{Resultados e Discussão}

A centrifugação foi analisada segundo algoritmo previamente desenvolvido pelo grupo de pesquisa do LDPB/UNICAMP ${ }^{1}$, com otimizações no algoritmo introduzidas neste trabalho. Para o Raio das fibras de fibrina, foi preparada uma planilha de cálculo utilizando a equação proposta por Yeromonahos et al. (2010) ${ }^{2}$.

Os resultados mostraram que a maior diferença entre os anticoagulantes está no empacotamento das células vermelhas na centrifugação (12\% maior para o CIT). Em consequência disso, maior volume de PRP foi obtido. A diferença na eficiência de recuperação de plaquetas foi em torno de $8 \%$ em favor do ACD-A. Fibras de fibrina mais finas que resultaram em menor tempo de agregação das plaquetas foram obtidas com ACD-A.

\section{Conclusões}

Na centrifugação o melhor desempenho foi devido ao CIT e na ativação ao ACD- A.

\section{Agradecimentos}

Os autores agradecem aos voluntários doadores e ao $\mathrm{PIBIC/CNPq}$ pelo suporte a este trabalho.

\footnotetext{
${ }^{1}$ Perez, A.G.M., Lichy, R., Rodrigues, A.A., Luzo, A.C.M., Lana, J.F.S.D., Belangero, W.D., Santana, M.H.A., Prediction and Modulation of Platelet Recovery by Discontinuous Centrifugation of Whole Blood for the Preparation of Pure Platelet-Rich Plasma. BioResearch Open Access 2, 307-314, 2013

2 Yeromonahos, C., Polack, B.b Caton, F. Nanostructure of the FibrinClot. Biophysical Journal 99, 2018-2027, 2010.
} 